\title{
The Pathogenic Component of the APOE-TOMM40 Region in Alzheimer's disease: Its Implications in Metabolomics and Pharmacogenomics
}

\section{Cacabelos $\mathbf{R}^{*}$}

Chair of Genomic Medicine, Camilo José Cela University, Madrid; EuroEspes Biomedical Research Center, Institute of Medical Science and Genomic Medicine, Corunna, Spain

*Corresponding author: Cacabelos R, Chair of Genomic Medicine Camilo José Cela University, Madrid, Spain, Tel no: 34918153131; E-mail: rcacabelos@ucjc.edu Rec date: Jul 29, 2014, Acc date: Jul 30, 2014, Pub date: Aug 7, 2014

Copyright: (C) 2014 Cacabelos. This is an open-access article distributed under the terms of the Creative Commons Attribution License, which permits unrestricted use, distribution, and reproduction in any medium, provided the original author and source are credited.

\section{Editorial}

The genetic and epigenetic defects identified so far in Alzheimer's disease (AD) include Mendelian mutations, susceptibility singlenucleotide polymorphisms (SNPs), mitochondrial DNA (mtDNA) mutations, and epigenetic changes. Mendelian mutations affect genes directly linked to $\mathrm{AD}$, including mutations in the amyloid beta precursor protein $(A P P)$ gene (21q21) (AD1), mutations in the presenilin 1 (PSEN1) gene (14q24.3) (AD3), and mutations in the presenilin 2 (PSEN2) gene (1q31-q42) (AD4) [1-2]. There are over 600 genes potentially associated with $\mathrm{AD}$, of which the top ten are $A P O E$ (19q13.2), BIN1 (2q14), CLU (8p21-p12), ABCA7 (19p13.3), CR1 (1q32), PICALM (11q14), MS4A6A (11q12.1), CD33 (19q13.3), $M S 4 A 4 E$ (11q12.2), and $C D 2 A P(6 \mathrm{p} 12)$.

Among susceptibility genes, the apolipoprotein $\mathrm{E}(A P O E)$ gene $(19 \mathrm{q} 13.2)(A D 2)$ is the most prevalent as a risk factor for $\mathrm{AD}$, especially in those subjects harboring the $A P O E-4$ allele [3], whereas carriers of the $A P O E-2$ allele are prone to longevity [4] and might be protected against dementia [5].

$A P O E$ is the prototypical paradigm of a pleiotropic gene with multifaceted activities in physiological and pathological conditions $[1,6]$. ApoE is consistently associated with the amyloid plaque marker for AD. APOE-4 may influence AD pathology by interacting with APP metabolism and $A \beta$ accumulation, enhancing hyperphosphorylation of tau protein and neurofibrillary tangle (NFT) formation, reducing choline acetyltransferase activity, increasing oxidative processes, modifying inflammation-related neuroimmunotrophic activity and glial activation, altering lipid metabolism, lipid transport and membrane biosynthesis in sprouting and synaptic remodeling, and inducing neuronal apoptosis [1,6-8]. In addition, multiple studies over the past two decades have demonstrated that APOE variants may affect the therapeutic response to anti-dementia drugs [9-17].

From studies designed to define APOE-related AD phenotypes, several conclusions can be drawn: (i) the age-at-onset is 5-10 years earlier in approximately $80 \%$ of $\mathrm{AD}$ cases harboring the $A P O E-4 / 4$ genotype; (ii) the serum levels of ApoE are lowest in $A P O E-4 / 4$, intermediate in $A P O E-3 / 3$ and $A P O E-3 / 4$, and highest in $A P O E-2 / 3$ and $A P O E-2 / 4$; (iii) serum cholesterol levels are higher in $A P O E-4 / 4$ than in the other genotypes; (iv) HDL-cholesterol levels tend to be lower in $A P O E-3$ homozygotes than in $A P O E-4$ allele carriers; (v) LDL-cholesterol levels are systematically higher in APOE-4/4 than in any other genotype; (vi) triglyceride levels are significantly lower in $A P O E-4 / 4$; (vii) nitric oxide levels are slightly lower in $A P O E-4 / 4$; (viii) serum and CSF $\mathrm{A} \beta$ levels tend to differ between $A P O E-4 / 4$ and the other most frequent genotypes ( $A P O E-3 / 3, A P O E-3 / 4$ ); (ix) blood histamine levels are dramatically reduced in $A P O E-4 / 4$ as compared with the other genotypes; $(\mathrm{x})$ brain atrophy and $\mathrm{AD}$ neuropathology is markedly increased in $A P O E-4 / 4>A P O E-3 / 4>A P O E-3 / 3$; (xi) brain mapping activity shows a significant increase in slow wave activity in APOE-4/4 from early stages of the disease; (xii) brain hemodynamics, as reflected by reduced brain blood flow velocity and increased pulsatility and resistance indices, is significantly worse in $A P O E-4 / 4$ (and in $A P O E-4$ carriers in general, as compared with $A P O E-3$ carriers); brain hypoperfusion and neocortical oxygenation is also more deficient in $A P O E-4$ carriers; (xiii) lymphocyte apoptosis is markedly enhanced in $A P O E-4$ carriers; (xiv) cognitive deterioration is faster in $A P O E-4 / 4$ patients than in carriers of any other $A P O E$ genotype; (xv) in approximately $3-8 \%$ of the $\mathrm{AD}$ cases, the presence of some dementia-related metabolic dysfunctions accumulates more in $A P O E-4$ carriers than in $A P O E-3$ carriers; (xvi) some behavioral disturbances, alterations in circadian rhythm patterns, and mood disorders are slightly more frequent in $A P O E-4$ carriers; (xvii) aortic and systemic atherosclerosis is also more frequent in APOE-4 carriers; (xviii) liver metabolism and transaminase activity also differ in $A P O E-4 / 4$ with respect to other genotypes; (xix) hypertension and other cardiovascular risk factors also accumulate in $A P O E-4$; and $(\mathrm{xx})$ $A P O E-4 / 4$ carriers are the poorest responders to conventional drugs. These 20 major phenotypic features clearly illustrate the biological disadvantage of $A P O E-4$ homozygotes and the potential consequences that these patients may experience when they receive pharmacological treatment for $\mathrm{AD}$ and/or concomitant pathologies [8-19].

The TOMM4O locus is located adjacent to and in linkage disequilibrium with $A P O E$ on $19 \mathrm{q} 13.2$. A poly $\mathrm{T}$ repeat in an intronic polymorphism (rs10524523) (intron 6) in the TOMM40 gene, which encodes an outer mitochondrial membrane translocase involved in the transport of amyloid- $\beta$ and other proteins into mitochondria, has been implicated in $\mathrm{AD}$ [20-33], and APOE-TOMM40 genotypes have been shown to modify disease risk and age at onset of symptoms [21-26,34]. A fixed-effect meta-analysis approach showed that rs4420638 at the TOMM40/APOE/APOC1 gene locus is associated with longevity $[35,36]$. Two independent associations with cognitive decline were found among European-Americans in the 19q13.32 region (rs769449, APOE intron; and rs115881343, TOMM40 intron); rs769449 was also associated with cognitive decline among African-Americans, but rs115881343 was not [37]. The APOE-TOMM4O genomic region is associated with cognitive aging [38] and with pathological cognitive decline [39].

Linnertz et al. [28] defined 3 allele groups for rs10524523 ('523'), based on the number of 'T'-residues: 'Short' (S, T $\leq 19)$, 'Long' (L, $20 \leq$ $\mathrm{T} \leq 29$ ) and 'Very Long' (VL, $\mathrm{T} \geq 30$ ). Roses et al. [22-25] reported that longer lengths of rs 10524523 are associated with a higher risk for lateonset Alzheimer's disease (LOAD); for $A P O E-3 / 4$ patients who developed LOAD after 60 years of age, individuals with long poly $\mathrm{T}$ repeats (19-39 nucleotides) linked to $A P O E-3$ develop LOAD on an 
average of 7 years earlier than individuals with shorter poly $\mathrm{T}$ repeats (11-16 nucleotides) linked to $A P O E-3[22,23,26]$.

Linnertz et al. [40] also investigated the genomic region spanning the TOMM4O and $A P O E$ genes, to determine whether intronic poly $\mathrm{T}$ (rs10524523) within this region affects expression of the $A P O E$ and TOMM40 genes in the brain of patients with LOAD. The expression of both genes was significantly increased with disease. Mean expression of $A P O E$ and TOMM4O mRNA levels was higher in VL homozygotes compared with $\mathrm{S}$ homozygotes in the temporal and occipital cortexes from normal and LOAD cases. The $523 \mathrm{VL}$ poly $\mathrm{T}$ resulted in significantly higher expression than the $\mathrm{S}$ poly $\mathrm{T}$. These results suggest that the 523 locus may contribute to LOAD susceptibility by modulating the expression of TOMM40 and/or APOE transcription [40]. Recent studies also suggest that the TOMM40 gene rs 10524523 ("523") variable length poly T repeat polymorphism is associated to a certain extent with similar $\mathrm{AD}$ phenotypes as those reported for $A P O E$, such as brain white matter changes [41,42] or different biomarkers [43-46]. In addition, the TOMM40 rs2075650 G allele may be a risk factor for the development of depression [47] and sporadic inclusion body myositis [48]. Different markers at the 19q13-q13.2 chromosomal region, including the rs2075650 and rs157590 (TOMM40), rs1064725 (APOC1), and rs429358 and rs7412 (APOE) SNPs also show association with primary progressive aphasia and the behavioral variant frontotemporal dementia [49].

The TOMM40/APOE/APOC1 loci have been associated with Creactive protein (CRP), a heritable biomarker of systemic inflammation and a predictor of cardiovascular disease (CVD) [50]. Genome-wide association studies (GWAS) have identified LDLcholesterol-associated loci near HMGCR, ABO and TOMM4O [51], and also an association of TOMM4O with blood lipid levels [52,53] and body mass index [54]. Genetic variants in TOMM40/APOE-C1-C2-C4 genes have also been found to be associated with multiple cardiovascular-related traits [55-57].

In a recent study [58], the structure of the $A P O E-T O M M 40$ region has been investigated in Spanish patients with dementia, as well as the influence of polymorphic variants in this genomic segment on the therapeutic response to a multifactorial treatment adapted to the pathogenic profile of the patients. The distribution and frequency of APOE genotypes was the following: $A P O E-2 / 3,8.26 \%$; $A P O E-2 / 4$, $1.96 \%$; $A P O E-3 / 3,51.52 \%$; $A P O E-3 / 4,33.04 \%$; and $A P O E-4 / 4,5.22 \%$. The distribution of 6 major TOMM40 poly T variants was: $18.37 \% \mathrm{~S} / \mathrm{S}$, 7.83\% S/L, 38.80\% S/VL, 1.52\% L/L, 7.17\% L/VL, and 26.31\% VL/VL. The $A P O E-2 / 3$ genotype was found to be associated with S/S (27.63\%), S/VL (51.32\%), and L/VL (21.05\%); $A P O E-2 / 4$ was associated with S/L (16.67\%), S/VL (38.89\%), L/VL (11.11\%), and VL/VL (33.33\%); $A P O E-3 / 3$ was associated with S/S (29.32\%), S/L (0.42\%), S/VL (47.26\%), L/VL (0.21\%), and VL/VL (22.79\%); $A P O E-3 / 4$ was associated with S/S (2.96\%), S/L (21.38\%), S/VL (28.29\%), L/VL (15.46\%), and VL/VL (31.91\%); and $A P O E-4 / 4$ was associated with S/L (4.17\%), S/VL (2.17\%), L/L (29.17\%), L/VL (33.33\%), and VL/VL (31.25\%). Likewise, the S/S genotype was associated with $A P O E-2 / 3$ (27.63\%), 3/3 (29.32\%), and 3/4 (2.96\%); S/L with $A P O E-2 / 4(16.67 \%)$, $3 / 3(0.42 \%), 3 / 4(21.38 \%)$, and $4 / 4(4.17 \%) ; \mathrm{S} / \mathrm{VL}$ with $A P O E-2 / 3$ (51.32\%), 2/4 (38.89\%), 3/3 (47.26\%), 3/4 (28.29\%), and 4/4 (2.08\%); $\mathrm{L} / \mathrm{L}$ was exclusively associated with $A P O E-4 / 4$ (100\%); L/VL with APOE-2/4 (11.11\%), 3/3(0.21\%), 3/4 (15.46\%), and 4/4 (33.33\%); and VL/VL with $A P O E-2 / 3$ (21.05\%), 2/4 (33.33\%), 3/3 (22.79\%), 3/4 (31.91\%), and $4 / 4(31.25 \%)$. S/VL and VL/VL are the only TOMM4O poly $\mathrm{T}$ genotypes which interact with all major $A P O E$ genotypes; in contrast, the $A P O E-4 / 4-T O M M 40-L / L$ association is unique, representing approximately $30 \%$ of $A P O E-4 / 4$ carriers [58]. This pioneering study also revealed that: (i) $A P O E-4$ carriers are the worst responders and $A P O E-3$ carriers are the best responders to conventional treatments; (ii) TOMM40 poly $T-S / S$ carriers are the best responders, VL/VL and S/VL carriers are intermediate responders, and $\mathrm{L} / \mathrm{L}$ carriers are the worst responders to treatment; (iii) patients harboring a large $(\mathrm{L})$ number of poly $\mathrm{T}$ repeats in intron 6 of the TOMM 40 gene (L/L or S/L genotypes) in haplotypes associated with $A P O E-4$ are the worst responders to treatment; (iv) patients with short (S) TOMM4O poly $\mathrm{T}$ variants ( $\mathrm{S} / \mathrm{S}$ genotype), and to a lesser extent S/VL and VL/VL carriers, in haplotypes with $A P O E-3$ are the best responders to treatment; and (v) in $100 \%$ of the cases, the $\mathrm{L} / \mathrm{L}$ genotype is exclusively associated with the $A P O E-4 / 4$ genotype, and this haplotype $(4 / 4-\mathrm{L} / \mathrm{L})$ is probably responsible for early onset of the disease, a faster cognitive decline, and a poor response to different treatments [58].

\section{References}

1. Cacabelos R, Fernandez-Novoa L, Lombardi V, Kubota Y, Takeda M (2005) Molecular genetics of Alzheimer's disease and aging. See comment in PubMed Commons below Methods Find Exp Clin Pharmacol 27 Suppl A: 1-573.

2. Bertram L, McQueen MB, Mullin K, Blacker D, Tanzi RE (2007) Systematic meta-analyses of Alzheimer disease genetic association studies: The AlzGene database. Nat Genet 39: 17-23.

3. Roses AD, Strittmatter WJ, Pericak-Vance MA, Corder EH, Saunders AM, et al. (1994) Clinical application of apolipoprotein E genotyping to Alzheimer's disease. See comment in PubMed Commons below Lancet 343: 1564-1565.

4. Schupf N, Barral S, Perls T, Newman A, Christensen K, et al. (2013) Apolipoprotein E and familial longevity. See comment in PubMed Commons below Neurobiol Aging 34: 1287-1291.

5. Corder EH, Saunders AM, Risch NJ, Strittmatter WJ, Schmechel DE, et al. (1994) Protective effect of apolipoprotein E type 2 allele for late onset Alzheimer disease. See comment in PubMed Commons below Nat Genet 7: 180-184.

6. Cacabelos R, Takeda M (2006) Pharmacogenomics, nutrigenomics and future therapeutics in Alzheimer's disease. Drugs Future 31(Suppl B): 5-146.

7. Cacabelos R (2003) The application of functional genomics to Alzheimer's disease. See comment in PubMed Commons below Pharmacogenomics 4: 597-621.

8. Cacabelos $\mathrm{R}$ (2008) Pharmacogenomics in Alzheimer's disease. See comment in PubMed Commons below Methods Mol Biol 448: 213-357.

9. Cacabelos R, Martínez-Bouza R (2011) Genomics and pharmacogenomics of dementia. See comment in PubMed Commons below CNS Neurosci Ther 17: 566-576.

10. Cacabelos R (2011) The path to personalized medicine in mental disorders. In: Ritsner MS (Ed) The handbook of neuropsychiatric biomarkers, endophenotypes and genes, vol. 4. Springer, Netherlands, pp. 3-63.

11. Cacabelos R (2009) Pharmacogenomics and therapeutic strategies for dementia. See comment in PubMed Commons below Expert Rev Mol Diagn 9: 567-611.

12. Cacabelos R, Fernández-Novoa L, Martínez-Bouza R, McKay A, Carril JC, et al. (2010) Future trends in the pharmacogenomics of brain disorders and dementia: Influence of APOE and CYP2D6 variants. Pharmaceuticals 3: 3040-3100.

13. Cacabelos R (2007) Donepezil in Alzheimer's disease: From conventional trials to pharmacogenetics. See comment in PubMed Commons below Neuropsychiatr Dis Treat 3: 303-333.

14. Cacabelos R, Llovo R, Fraile C, Fernández-Novoa L (2007) Pharmacogenetic aspects of therapy with cholinesterase inhibitors: the role 
of CYP2D6 in Alzheimer's disease pharmacogenetics. See comment in PubMed Commons below Curr Alzheimer Res 4: 479-500.

15. Cacabelos R (2007) Molecular pathology and pharmacogenomics in Alzheimer's disease: polygenic-related effects of multifactorial treatments on cognition, anxiety and depression. See comment in PubMed Commons below Methods Find Exp Clin Pharmacol 29 Suppl A: 1-91.

16. Roses AD (2004) Pharmacogenetics and drug development: the path to safer and more effective drugs. See comment in PubMed Commons below Nat Rev Genet 5: 645-656.

17. Roses AD (2008) Pharmacogenetics in drug discovery and development: a translational perspective. See comment in PubMed Commons below Nat Rev Drug Discov 7: 807-817.

18. Cacabelos R (2012) Pharmacogenomics of central nervous system (CNS) drugs. Drug Dev Res 73: 461-476.

19. Cacabelos R, Cacabelos P, Torrellas C, Tellado I, Carril JC (In press) Pharmacogenomics of Alzheimer's disease. Novel therapeutic strategies for Drug development. Methods Mol Biol.

20. Takei N, Miyashita A, Tsukie T, Arai H, Asada T, et al. (2009) Genetic association study on in and around the APOE in late-onset Alzheimer disease in Japanese. See comment in PubMed Commons below Genomics 93: 441-448.

21. Potkin SG, Guffanti G, Lakatos A, Turner JA, Kruggel F, et al. (2009) Hippocampal atrophy as a quantitative trait in a genome-wide association study identifying novel susceptibility genes for Alzheimer's disease. See comment in PubMed Commons below PLoS One 4: e6501.

22. Roses AD (2010) An inherited variable poly-T repeat genotype in TOMM40 in Alzheimer disease. See comment in PubMed Commons below Arch Neurol 67: 536-541.

23. Roses AD, Lutz MW, Amrine-Madsen H, Saunders AM, Crenshaw DG, et al. (2010) A TOMM40 variable-length polymorphism predicts the age of late-onset Alzheimer's disease. Pharmacogenomics J 10: 375-384.

24. Roses AD, Saunders AM, Lutz MW, Zhang N, Hariri AR, et al. (2014) New applications of disease genetics and pharmacogenetics to drug development. See comment in PubMed Commons below Curr Opin Pharmacol 14: 81-89.

25. Roses AD, Lutz MW, Crenshaw DG, Grossman I, Saunders AM, et al. (2013) TOMM40 and APOE: Requirements for replication studies of association with age of disease onset and enrichment of a clinical trial. See comment in PubMed Commons below Alzheimers Dement 9: 132-136.

26. Lutz MW, Crenshaw DG, Saunders AM, Roses AD (2010) Genetic variation at a single locus and age of onset for Alzheimer's disease. See comment in PubMed Commons below Alzheimers Dement 6: 125-131.

27. Shen L, Kim S, Risacher SL, Nho K, Swaminathan S, et al. (2010) Whole genome association study of brain-wide imaging phenotypes for identifying quantitative trait loci in $\mathrm{MCI}$ and $\mathrm{AD}$ : A study of the ADNI cohort. See comment in PubMed Commons below Neuroimage 53: 1051-1063.

28. Linnertz C, Saunders AM, Lutz MW, Crenshaw DM, Grossman I, et al. (2012) Characterization of the poly-T variant in the TOMM40 gene in diverse populations. See comment in PubMed Commons below PLoS One 7: e30994.

29. Omoumi A, Fok A, Greenwood T, Sadovnick AD, Feldman HH, et al. (2014) Evaluation of late-onset Alzheimer disease genetic susceptibility risks in a Canadian population. See comment in PubMed Commons below Neurobiol Aging 35: 936.

30. Bagnoli S, Piaceri I, Tedde A, Bessi V, Bracco L, et al. (2013) TOMM40 polymorphisms in Italian Alzheimer's disease and frontotemporal dementia patients. See comment in PubMed Commons below Neurol Sci 34: 995-998.

31. Ma XY, Yu JT, Wang W, Wang HF, Liu QY, et al. (2013) Association of TOMM40 polymorphisms with late-onset Alzheimer's disease in a Northern Han Chinese population. See comment in PubMed Commons below Neuromolecular Med 15: 279-287.

32. Valant V, Keenan BT, Anderson CD, Shulman JM, Devan WJ, et al. (2012) TOMM40 in Cerebral Amyloid Angiopathy Related Intracerebral Hemorrhage: Comparative Genetic Analysis with Alzheimer's Disease. Transl Stroke Res 3: 102-112.
33. Vounou M, Janousova E, Wolz R, Stein JL, Thompson PM, et al. (2012) Sparse reduced-rank regression detects genetic associations with voxel-wise longitudinal phenotypes in Alzheimer's disease. See comment in PubMed Commons below Neuroimage 60: 700-716.

34. Bernardi L, Gallo M, Anfossi M, Conidi ME, Colao R, et al. (2013) Role of TOMM40 rs10524523 polymorphism in onset of alzheimer's disease caused by the PSEN1 M146L mutation. See comment in PubMed Commons below J Alzheimers Dis 37: 285-289.

35. Sebastiani P, Solovieff N, Dewan AT, Walsh KM, Puca A, et al. (2012) Genetic signatures of exceptional longevity in humans. See comment in PubMed Commons below PLoS One 7: e29848.

36. Beekman M, Blanché H, Perola M, Hervonen A, Bezrukov V, et al. (2013) Genome-wide linkage analysis for human longevity: Genetics of Healthy Aging Study. See comment in PubMed Commons below Aging Cell 12: 184-193.

37. Zhang C, Pierce BL (2014) Genetic susceptibility to accelerated cognitive decline in the US Health and Retirement Study. See comment in PubMed Commons below Neurobiol Aging 35: 1512.

38. Davies G, Harris SE, Reynolds CA, Payton A, Knight HM, et al. (2014) A genome-wide association study implicates the APOE locus in nonpathological cognitive ageing. See comment in PubMed Commons below Mol Psychiatry 19: 76-87.

39. Hayden KM, McEvoy JM, Linnertz C, Attix D, Kuchibhatla M, et al. (2012) A homopolymer polymorphism in the TOMM40 gene contributes to cognitive performance in aging. See comment in PubMed Commons below Alzheimers Dement 8: 381-388.

40. Linnertz C, Anderson L, Gottschalk W, Crenshaw D, Lutz MW, et al. (2014) The cis-regulatory effect of an Alzheimer's disease-associated poly-T locus on expression of TOMM40 and apolipoprotein E genes. See comment in PubMed Commons below Alzheimers Dement .

41. Lyall DM, Harris SE, Bastin ME, Muñoz Maniega S, Murray C, et al. (2014) Alzheimer's disease susceptibility genes APOE and TOMM40, and brain white matter integrity in the Lothian Birth Cohort 1936. Neurobiol Aging 35: 1513.e25-33.

42. Johnson SC, La Rue A, Hermann BP, Xu G, Koscik RL, et al. (2011) The effect of TOMM40 poly-T length on gray matter volume and cognition in middle-aged persons with APOE $\hat{\mathrm{I}} \mu 3 / \hat{\mathrm{I}} \mu 3$ genotype. See comment in PubMed Commons below Alzheimers Dement 7: 456-465.

43. Elias-Sonnenschein LS, Helisalmi S, Natunen T, Hall A, Paajanen T, et al (2013) Genetic loci associated with Alzheimer's disease and cerebrospinal fluid biomarkers in a Finnish case-control cohort. See comment in PubMed Commons below PLoS One 8: e59676.

44. Silver M, Janousova E, Hua X, Thompson PM, Montana G; Alzheimer's Disease Neuroimaging Initiative (2012) Identification of gene pathways implicated in Alzheimer's disease using longitudinal imaging phenotypes with sparse regression. See comment in PubMed Commons below Neuroimage 63: 1681-1694.

45. Kim S, Swaminathan S, Shen L, Risacher SL, Nho K, et al. (2011) Genomewide association study of CSF biomarkers Abeta1-42, t-tau, and p-tau181p in the ADNI cohort. See comment in PubMed Commons below Neurology 76: 69-79.

46. Bruno D, Pomara N, Nierenberg J, Ritchie JC, Lutz MW, et al. (2012) Levels of cerebrospinal fluid neurofilament light protein in healthy elderly vary as a function of TOMM40 variants. Exp Gerontol 47: 347-352.

47. McFarquhar M, Elliott R, McKie S, Thomas E, Downey D, et al. (2014) TOMM40 rs2075650 may represent a new candidate gene for vulnerability to major depressive disorder. See comment in PubMed Commons below Neuropsychopharmacology 39: 1743-1753.

48. Mastaglia FL, Rojana-udomsart A, James I, Needham M, Day TJ, et al. (2013) Polymorphism in the TOMM40 gene modifies the risk of developing sporadic inclusion body myositis and the age of onset of symptoms. See comment in PubMed Commons below Neuromuscul Disord 23: 969-974.

49. Seripa D, Bizzarro A, Pilotto A, Palmieri O, Panza F, et al. (2012) TOMM40, APOE, and APOC1 in primary progressive aphasia and 
Citation: Cacabelos R (2014) The Pathogenic Component of the APOE-TOMM40 Region in Alzheimer's disease: Its Implications in Metabolomics and Pharmacogenomics. Metabolomics 4: 1000e129. doi:10.4172/2153-0769.1000e129

Page 4 of 4

frontotemporal dementia. See comment in PubMed Commons below J Alzheimers Dis 31: 731-740.

50. Ellis J, Lange EM, Li J, Dupuis J, Baumert J, et al. (2014) Large multiethnic Candidate Gene Study for C-reactive protein levels: identification of a novel association at CD36 in African Americans. Hum Genet.

51. Zhou L, He M, Mo Z, Wu C, Yang H, et al. (2013) A genome wide association study identifies common variants associated with lipid levels in the Chinese population. See comment in PubMed Commons below PLoS One 8: e82420.

52. Zhang Z, Tao L, Chen Z, Zhou D, Kan M, et al. (2011) Association of genetic loci with blood lipids in the Chinese population. See comment in PubMed Commons below PLoS One 6: e27305.

53. Jiang R, Brummett BH, Hauser ER, Babyak MA, Siegler IC, et al. (2013) Chronic family stress moderates the association between a TOMM40 variant and triglyceride levels in two independent Caucasian samples. See comment in PubMed Commons below Biol Psychol 93: 184-189.

54. Guo Y, Lanktree MB, Taylor KC, Hakonarson H, Lange LA, et al. (2013) Gene-centric meta-analyses of 108912 individuals confirm known body mass index loci and reveal three novel signals. See comment in PubMed Commons below Hum Mol Genet 22: 184-201.

55. Middelberg RP, Ferreira MA, Henders AK, Heath AC, Madden PA, et al. (2011) Genetic variants in LPL, OASL and TOMM40/APOE-C1-C2-C4 genes are associated with multiple cardiovascular-related traits. See comment in PubMed Commons below BMC Med Genet 12: 123.

56. Jeemon P, Pettigrew K, Sainsbury C, Prabhakaran D, Padmanabhan S (2011) Implications of discoveries from genome-wide association studies in current cardiovascular practice. See comment in PubMed Commons below World J Cardiol 3: 230-247.

57. Ronald J, Rajagopalan R, Ranchalis JE, Marshall JK, Hatsukami TS, et al. (2009) Analysis of recently identified dyslipidemia alleles reveals two loci that contribute to risk for carotid artery disease. See comment in PubMed Commons below Lipids Health Dis 8: 52 .

58. Cacabelos R, Goldgaber D, Vostrov A, Matsuki H, Torrellas C, et al (2014)APOE-TOMM40 in the Pharmacogenomics of Dementia. J Pharmacogenomics Pharmacoproteomics 5: 135. 